Article

\title{
Effect of Aging Treatment on Microstructural Evolution of Rapidly Solidified Eutectic $\mathrm{Sn}-\mathrm{Pb}$ Alloy Powders
}

\author{
Jianfeng Yan ${ }^{1,2, *}$, Dezhi Zhu ${ }^{1}$, Yingjie Liu ${ }^{2}$ and Jun $\mathrm{Xu}^{2}$ \\ 1 Department of Mechanical Engineering, Tsinghua University, Beijing 100084, China; \\ zdz18@mails.tsinghua.edu.cn \\ 2 General Research Institute for Non-ferrous Metals, Beijing 100088, China; liuyingjie8686@163.com (Y.L.); \\ xujun@grinm.com (J.X.) \\ * Correspondence: yanjianfeng@tsinghua.edu.cn
}

Received: 3 January 2019; Accepted: 22 January 2019; Published: 24 January 2019

\begin{abstract}
The microstructural stability of rapidly solidified eutectic $\mathrm{Sn}-\mathrm{Pb}$ alloy solder powders was investigated through aging at room temperature $\left(25^{\circ} \mathrm{C}\right)$ and temperatures of $40{ }^{\circ} \mathrm{C}-120^{\circ} \mathrm{C}$. The coarsening behavior of the $\mathrm{Pb}$-rich phase both at room and elevated temperatures was observed. The evident coarsening of the Pb-rich phase was detected upon storage after 40 days. At elevated temperatures, a similar sequence of $\mathrm{Pb}$-rich phase coarsening was observed; however, it occurred substantially more quickly. Pb-rich coarsening rate kinetics at different temperatures were estimated using the Arrhenius equation. The apparent activation energy was $45.53 \pm 4.23 \mathrm{KJ} / \mathrm{mol}$, which indicates that grain boundary diffusion is a crucial mass transport mechanism controlling $\mathrm{Pb}$-rich phase coarsening under annealing.
\end{abstract}

Keywords: coarsening; $\mathrm{Sn}-\mathrm{Pb}$ alloy powders; aging treatment; microstructure

\section{Introduction}

Eutectic $\mathrm{Sn}-\mathrm{Pb}$ is the most crucial solder alloy with excellent electrical conductivity, good wettability, acceptable plasticity and low melting point properties [1]. In previous decades, it has been used as a joining material for the packaging and interconnection of electronic components and devices, and as solders for temperature-sensitive components, optoelectronics modules, printed circuit, plumbing and assembly of sheet metal parts [2-4]. It has also played an important role in a number of other industrial applications, such as water piping, beverage cans, and automobile bodies [5-7]. $\mathrm{Chu}$ et al. proposed a new technology for quenching $\mathrm{Sn}-\mathrm{Pb}$ droplets, and a higher cooling rate was obtained using this method [8]. Li et al. predicted the nucleation kinetics of $\mathrm{Sn}-\mathrm{Pb}$ droplets through combining the nucleation temperature and droplet motion [9]. The solidification behavior of $\mathrm{Sn}-\mathrm{Pb}$ droplets was investigated based on the microstructure and solidification path [10]. Melt atomization is a dominant technique and commercially used to yield metal and alloy powders, including electronic grade solder powders [11-13]. Before preparing a solder paste by mixing solder powders with flux, storage or transport is generally necessary. During this period, microstructural coarsening of the solder powder is observed. However, few studies have investigated the microstructural evolution of rapidly solidified eutectic $\mathrm{Sn}-\mathrm{Pb}$ alloy powders.

Reducing the free energy is the driving force behind coarsening for obtaining a more stable microstructure [14,15]. Gan et al. reported the size effect of $\mathrm{Sn}-\mathrm{Pb}$ microstructures on microdevices, and they indicated that stable microstructures are crucial in several applications [16]. The effect of the two primary phases on $\mathrm{Sn}-\mathrm{Pb}$ microstructures was studied using thermal analysis method [17]. 
Zhao et al. investigated the effect of processing conditions on the particle formation of $\mathrm{Sn}-37 \mathrm{wt} \% \mathrm{~Pb}$, and adequate clearance is essential based on the results [18].

Because a solder paste is affected by the quality of the powder, studying the microstructural evolution of rapidly solidified solder powders at room or elevated temperature is essential. However, little information presently exists on the morphology evolution of eutectic $\mathrm{Sn}-\mathrm{Pb}$ alloy powders. Therefore, in this study, the microstructures and stability of eutectic $\mathrm{Sn}-\mathrm{Pb}$ alloy powders generated through atomization were investigated. The microstructural evolution of eutectic $\mathrm{Sn}-\mathrm{Pb}$ alloy powders at ambient and elevated temperature was studied. Moreover, the Pb-rich coarsening rate kinetics and diffusion mechanism in $\mathrm{Sn}-\mathrm{Pb}$ alloy powders produced through atomization were discussed.

\section{Experimental Procedure}

A $\mathrm{Sn}-\mathrm{Pb}$ eutectic solder $(\mathrm{Sn}-37 \mathrm{wt} \% \mathrm{~Pb})$ used for atomization in this study was purchased from commercially $\mathrm{Sn}$ and $\mathrm{Pb}$ (purity of $99.99 \%$ ). A master alloy was obtained through melting in an induction furnace. Atomization was performed in a centrifugal atomizer at a cooling rate of $103-105{ }^{\circ} \mathrm{C} / \mathrm{s}$ under the protection of nitrogen atmosphere. $\mathrm{Sn}-\mathrm{Pb}$ solder powders were obtained after the rapid solidification of alloy droplets.

An aging treatment was performed in air at room temperature for different numbers of days and at temperatures of $40{ }^{\circ} \mathrm{C}, 60^{\circ} \mathrm{C}, 90^{\circ} \mathrm{C}$, and $120^{\circ} \mathrm{C}$. After rapid solidification, the powder samples were immediately placed in an oven.

Microstructures of $\mathrm{Sn}-\mathrm{Pb}$ were prepared using the following metallographic procedure. The powders were encased in epoxy resin and then sectioned, polished, and etched for microstructure examination. The polished samples were etched using a solution of 5 vol. $\% \mathrm{HCl}+95$ vol. $\% \mathrm{C}_{2} \mathrm{H}_{5} \mathrm{OH}$. The microstructures of both the powders and polished and etched specimens were examined through scanning electron microscopy (SEM). SEM micrographs were obtained in secondary-electron and backscattered-electron (BSE) modes.

\section{Results and Discussion}

The general features of the microstructure of $\mathrm{Sn}-\mathrm{Pb}$ alloy solders can be understood from the $\mathrm{Sn}-\mathrm{Pb}$ binary alloy phase diagram (Figure 1). With decreasing melt temperature, the first precipitated solids are lead primaries, which contained approximately $19 \mathrm{wt} \%$ of dissolved $\mathrm{Sn}$. Moreover, undercooling is generally required to nucleate $\mathrm{Sn}$, and the solidification of the primary eutectic matrix may occur at temperatures less than the equilibrium temperature of the eutectic $\mathrm{Sn}-\mathrm{Pb}$ alloy $\left(183^{\circ} \mathrm{C}\right)$ [19]. The solid solubility between $\mathrm{Sn}$ and $\mathrm{Pb}$ is limited, and Sn-rich and $\mathrm{Pb}$-rich phases are separated. In general, a lamellar eutectic structure, which comprises alternating plates of Sn-rich and $\mathrm{Pb}$-rich phases, appears through the slow solidification of binary alloys.

The solidified microstructure can be altered by changing the solidification rate or undercooling degree. With increasing melt undercooling, the lamellar eutectic structure may transform into an anomalous eutectic microstructure [20]. During centrifugal atomization, the melt droplets are solidified at strong undercooling, and the formation of a lamellar structure is suppressed. The resulting microstructure is a mixture of fine $\mathrm{Pb}$-rich and $\mathrm{Sn}$-rich solid phases. Figure 2 presents an SEM micrograph of the centrifugally atomized eutectic $\mathrm{Sn}-\mathrm{Pb}$ powders, which exhibit a fine structure immediately after solidification. Dark and light regions in the micrograph are $\mathrm{Sn}$-rich and $\mathrm{Pb}$-rich phases, respectively. The Pb-rich phase is finely dispersed in the Sn-rich matrix. 


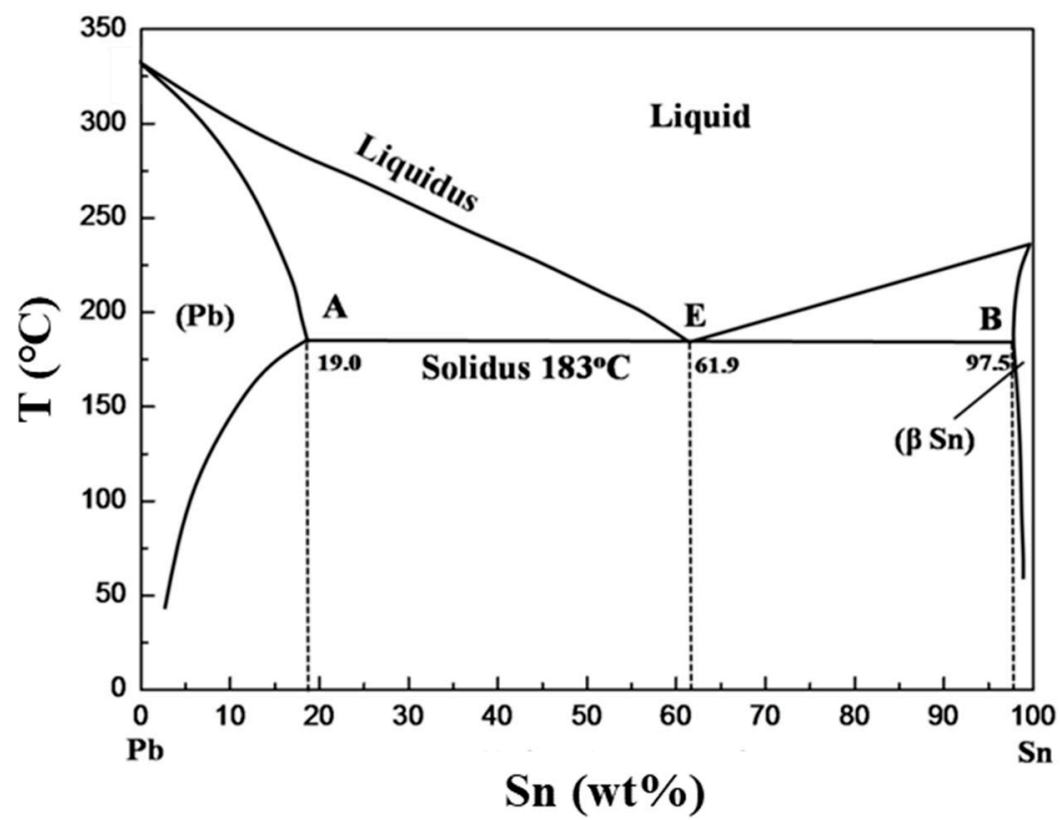

Figure 1. Sn-Pb binary alloy phase diagram.
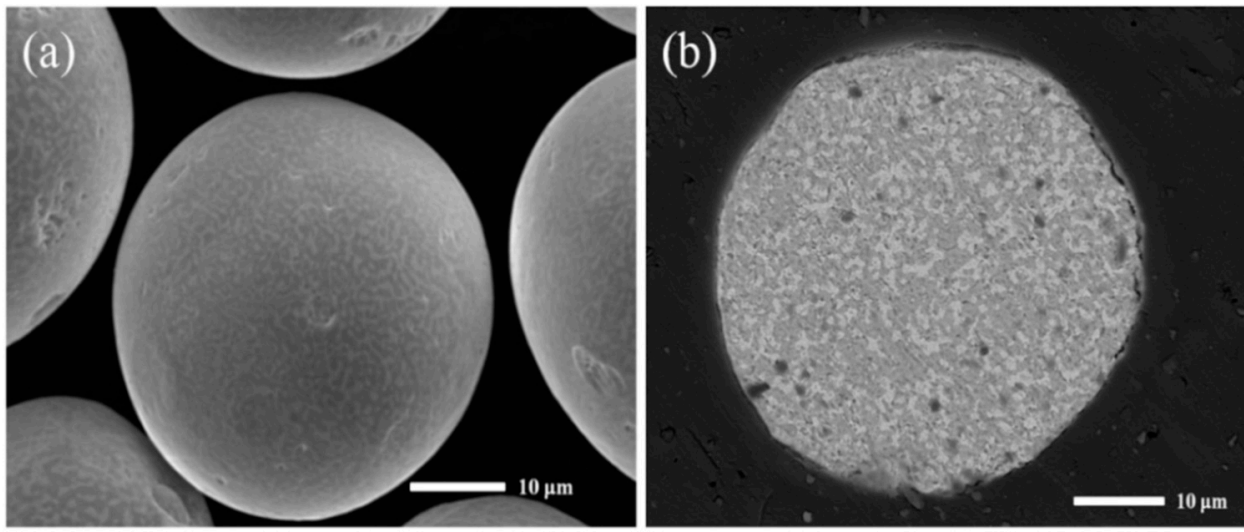

Figure 2. Microstructure of eutectic $\mathrm{Sn}-\mathrm{Pb}$ alloy powder. (a) The surface morphology, and (b) cross-sectional microstructure.

\subsection{Effect of Aging on the Microstructure of Solder Powder}

Figure 3 displays SEM images of the rapidly solidified eutectic Sn-Pb37 powder after aging at ambient temperature for different numbers of days. Even for aging at room temperature, coarsening of the microstructure is observed. A microstructure with an evident increase in the Pb-rich phase is observed after aging for 40 days. Moreover, some small particles are observed around the large particles in the $\mathrm{Pb}$-rich-phase-coarsened microstructure. This observation indicates that the large $\mathrm{Pb}$-rich phase particles grow at the expense of other particles rather than through a continuous nucleation and growth process. Structures formed during atomization generally have high interfacial areas and nonequilibrium solute concentration, because of the rapid solidification that occurs. This behavior is observed because of the need to reduce the overall energy of the system by decreasing the interfacial area. Sufficient thermal energy is required to reduce the energy of the system through diffusion even at room temperature.

Figure 4 presents the cross-sectional microstructure of rapidly solidified Sn-Pb37 powder aged for different numbers of days. No microsegregation of the Pb-rich phase was detected during growth. This observation illustrates that the $\mathrm{Pb}$-rich phase in $\mathrm{Sn}-\mathrm{Pb} 37$ powder coarsened through atom diffusion, with $\mathrm{Pb}$ particles becoming fewer in number, more spherical, and much larger during room temperature 
aging, indicating that the microstructure of the $\mathrm{Sn}-\mathrm{Pb} 37$ powder evolves even at room temperature. Because some material properties depend on the material's microstructure, the effect of microstructure coarsening at room temperature should be considered.
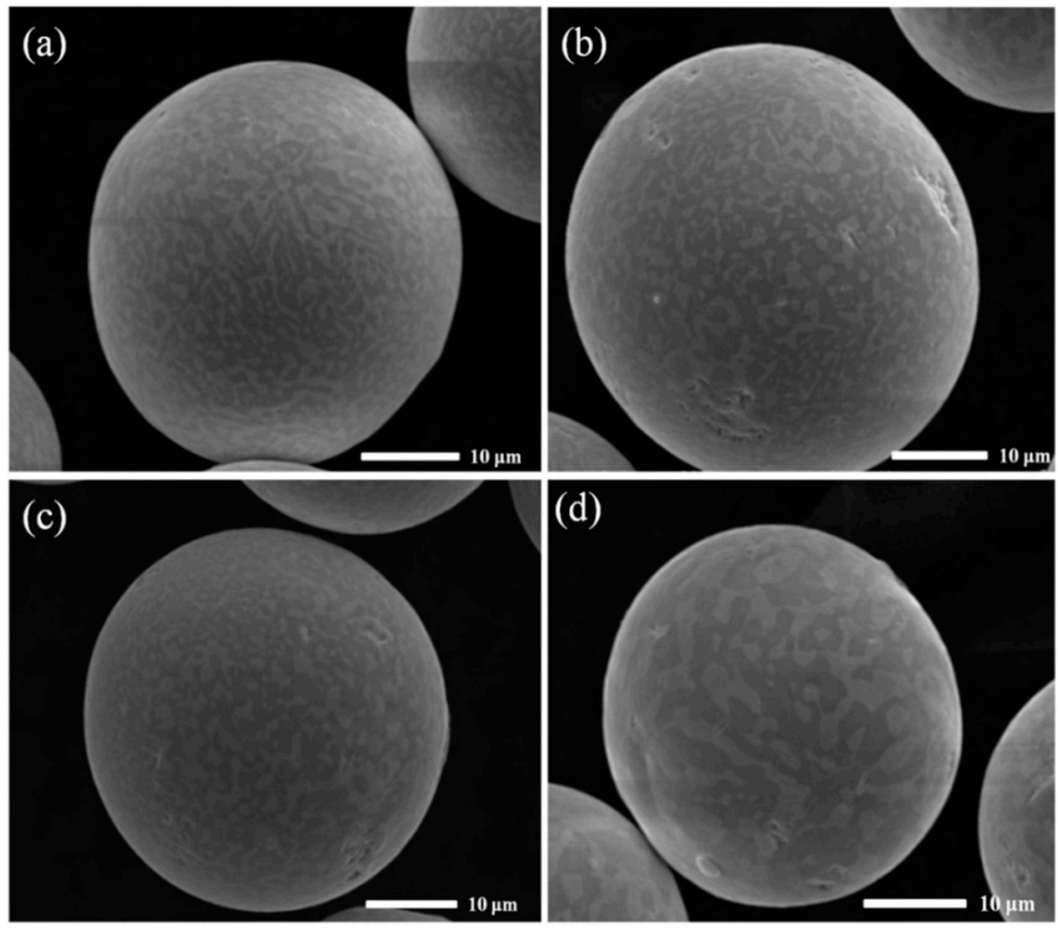

Figure 3. Scanning electron microscopy (SEM) images of rapidly solidified eutectic Sn-Pb37 powder after aging for (a) 7, (b) 21, (c) 29, and (d) 40 days.
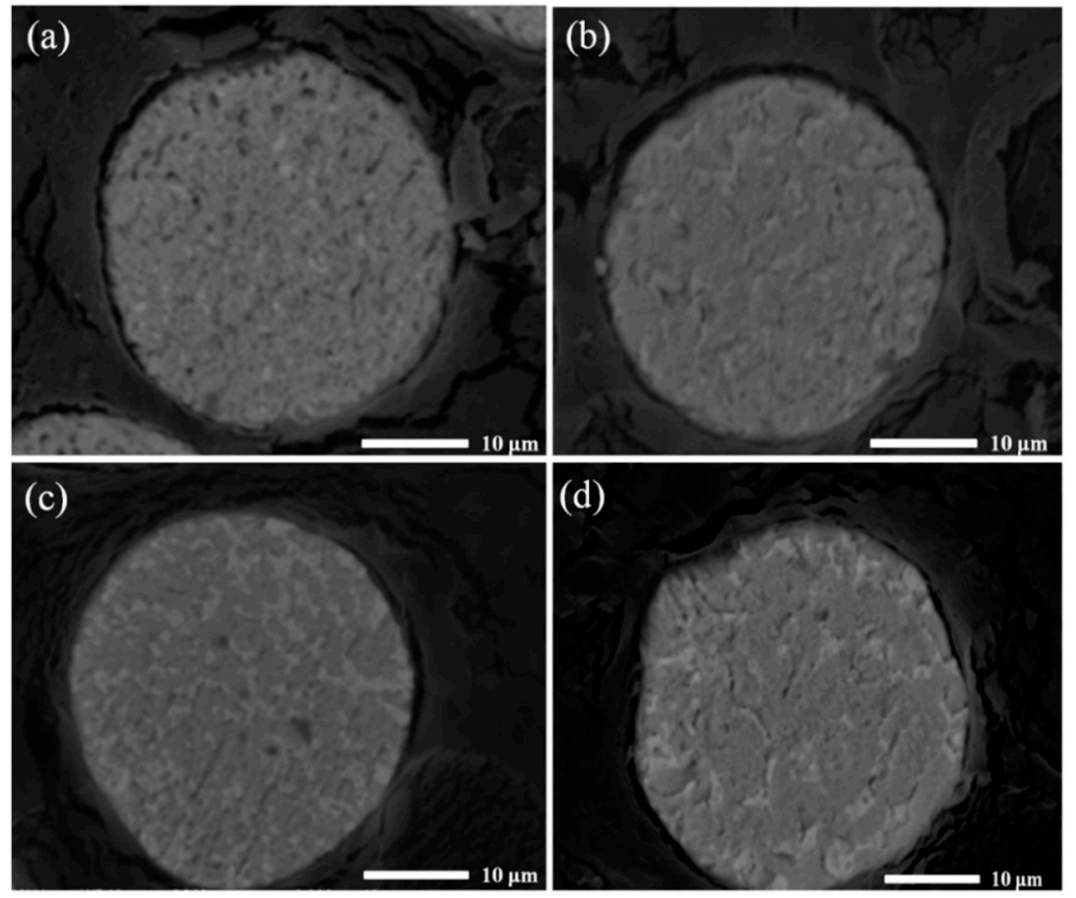

Figure 4. Cross-sectional microstructure of rapidly solidified Sn-Pb37 powder after aging for (a) 7, (b) 21, (c) 29, and (d) 40 days. 


\subsection{Effect of Heat Treatment on the Microstructure of Solder Powder}

To evaluate the effect of heating on microstructure evolution, the aging process was performed at elevated temperatures. Figure 5 presents SEM images of the eutectic Sn-Pb37 powder after heat treatment for 1 day in air at temperatures from $40{ }^{\circ} \mathrm{C}$ to $120^{\circ} \mathrm{C}$. Figure 6 shows the corresponding SEM micrographs of a cross-section through the powder. Microstructure coarsening similar to that caused by aging at room temperature occurs. However, the coarsening occurs more rapidly at elevated temperatures. The microstructure is coarsened to the same degree after aging at $120^{\circ} \mathrm{C}$ for 1 day as in aging for more than 1 month at room temperature.

The aging process in the alloy powder is the same at elevated temperatures as at room temperature; however, it occurs considerably more quickly at elevated temperatures. This indicates that the thermal diffusion coefficient between tin and lead is considerably higher for a higher aging temperature.

Precipitation occurs with a further increase in aging temperature. Figure 7 shows SEM images of $\mathrm{Sn}-\mathrm{Pb} 37$ powder after aging at $150^{\circ} \mathrm{C}$ for 3 days, wherein several small particles were precipitated. The solubility of tin in lead at $150{ }^{\circ} \mathrm{C}$ is approximately $10 \mathrm{wt} \%$, and thus some redissolution of the tin phase may be observed. After cooling to room temperature, the new precipitates are observed to have reduced tin solubility in lead.
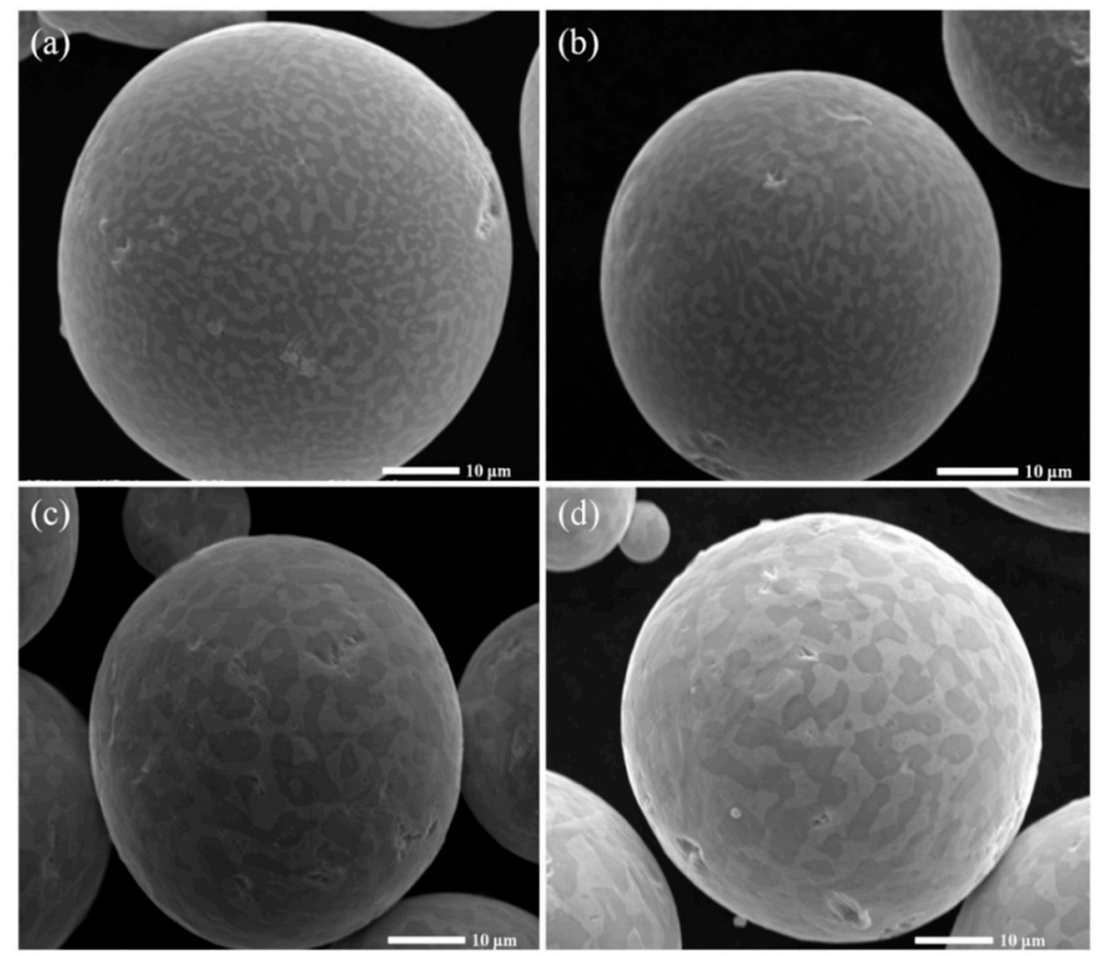

Figure 5. $\mathrm{SEM}$ images of rapidly solidified eutectic $\mathrm{Sn}-\mathrm{Pb} 37$ powder after heat treatment for 1 day in air at (a) $40^{\circ} \mathrm{C}$, (b) $60^{\circ} \mathrm{C}$, (c) $90^{\circ} \mathrm{C}$, and (d) $120^{\circ} \mathrm{C}$. 

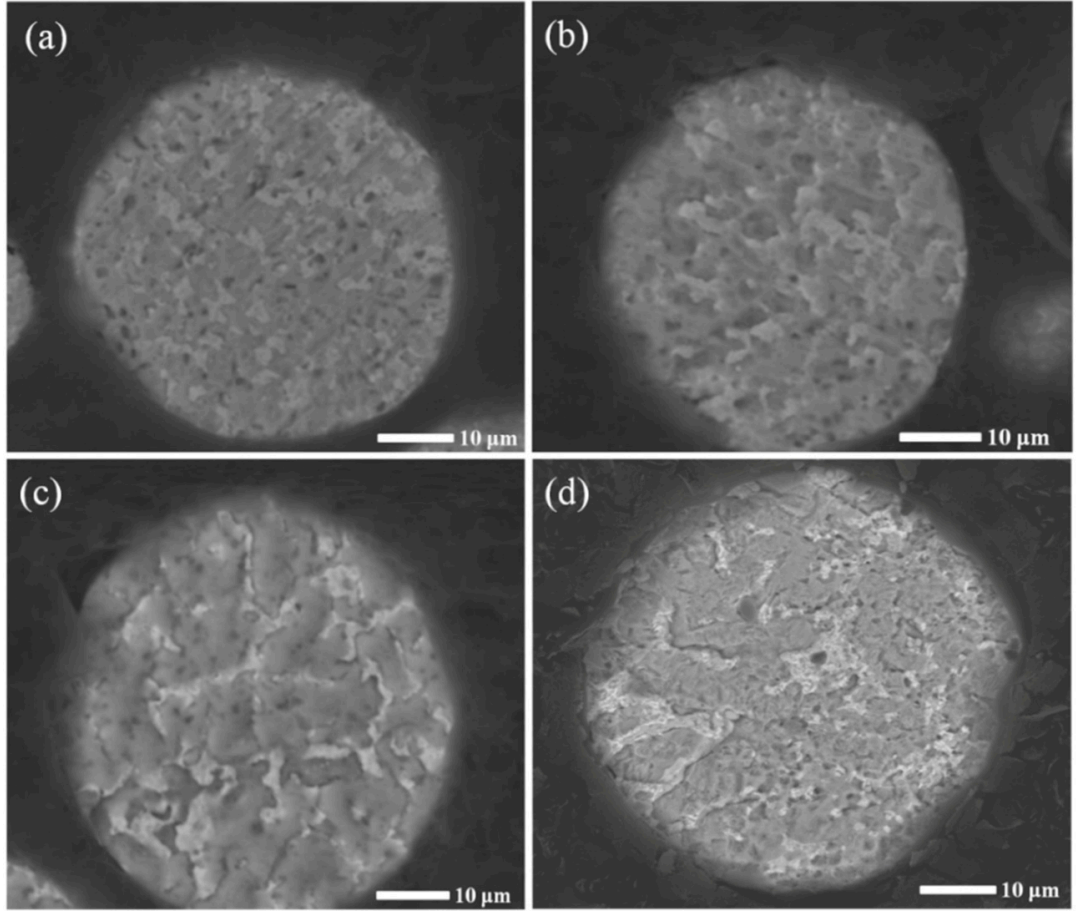

Figure 6. Cross-sectional microstructure of rapidly solidified eutectic $\mathrm{Sn}-\mathrm{Pb} 37$ powder after heat treatment for 1 day in air at (a) $40{ }^{\circ} \mathrm{C}$, (b) $60^{\circ} \mathrm{C}$, (c) $90^{\circ} \mathrm{C}$, and (d) $120^{\circ} \mathrm{C}$.

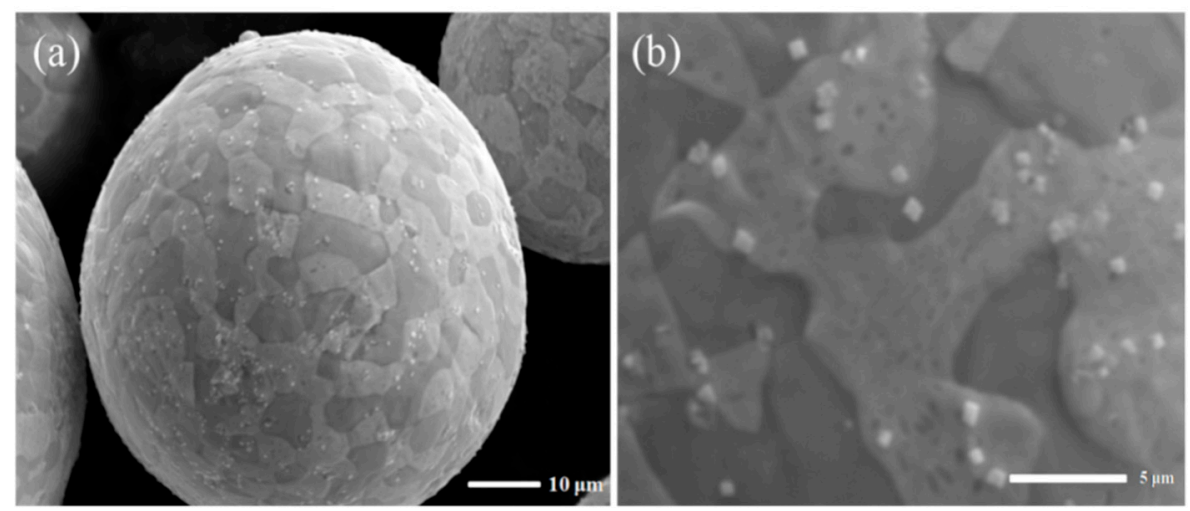

Figure 7. SEM images show the precipitate particles in the powders after aging at $150{ }^{\circ} \mathrm{C}$ for 3 days.

The coarsening kinetics of $\mathrm{Pb}$-rich particles at different aging temperatures can be interpreted using the Arrhenius law. The Pb-rich phase size is measured using the intercept method [21]. Similar to that of conventional materials, the growth of $\mathrm{Pb}$-rich particles can be described using the following equation:

$$
\mathrm{D}^{n}-D_{o}^{n}=k(T) t,
$$

where $D$ and $D_{o}$ are the average size of the $\mathrm{Pb}$-rich phase and initial $\mathrm{Pb}$-rich phase size before aging treatment, respectively; $k, T$, and $t$ represent a constant, the temperature, and time, respectively. The grain growth constant is temperature dependent:

$$
k(T) \propto e^{-Q / k_{b} T},
$$

where $Q$ and $k_{b}$ are the activation energy and Boltzmann constant, respectively. 
Therefore, the grain growth models for Pb-rich phase coarsening can be expressed using the following equation, which is in agreement with the models [22]:

$$
\mathrm{D}^{n}-D_{o}^{n}=K_{o} \exp (-Q / R T) t
$$

where $D$ and $D_{o}$ are the phase size after annealing for different durations and the initial phase size, respectively. $T, n, K_{o}$, and $Q$ are the temperature, phase size exponent, pre-exponential factor, and activation energy, respectively.

According to coarsening theory $[23,24]$, the growth exponent $n=4$ is used for the coarsening of $\mathrm{Pb}$-rich particles, in which the coarsening process is controlled through grain boundary solution diffusion. The growth kinetics of $\mathrm{Pb}$-rich phase particles are provided by

$$
\mathrm{D}^{4}-\mathrm{D}_{o}^{4}=K_{o} \exp (-Q / R T) t
$$

Figure 8 plots $\ln \left(\mathrm{D}^{4}-\mathrm{D}_{\mathrm{o}}^{4}\right)$ versus $1 / \mathrm{T}$ for the annealing of $\mathrm{Sn}-\mathrm{Pb} 37$ powder based on the $\mathrm{Pb}$-rich particle coarsening analysis. A straight line through the data points provides an activation energy of $Q=45.53 \pm 4.23 \mathrm{~kJ} / \mathrm{mol}$, which is consistent with the activation energy of grain boundary diffusion in $\mathrm{Sn}$ and $\mathrm{Pb}$ [21]. This observation is also consistent with the value reported for the thermal annealing of $\mathrm{Pb}$-phase growth, which is controlled by grain boundary diffusion.

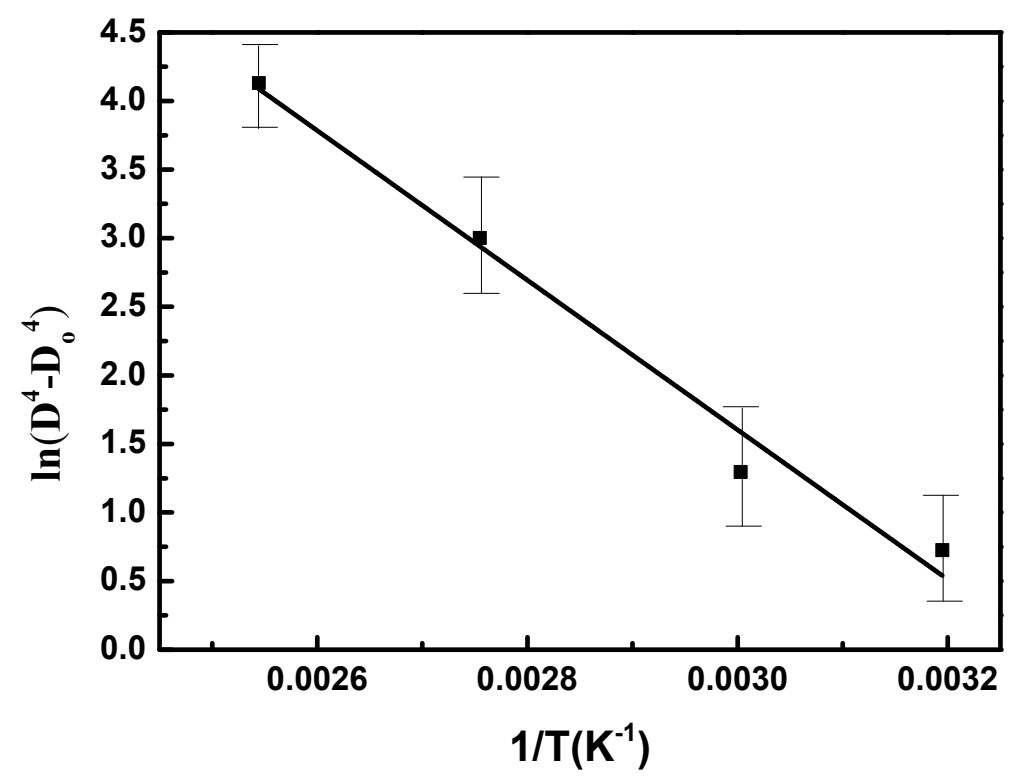

Figure 8. $\ln \left(D^{4}-D_{\mathrm{o}}{ }^{4}\right)$ versus $1 / T$ during $\mathrm{Pb}$-rich phase coarsening. Slope of solid line reveals an activation energy of $Q=45.53 \pm 4.23 \mathrm{~kJ} / \mathrm{mol}$.

\section{Conclusions}

The effects of aging treatment on the microstructural evolution of rapidly solidified eutectic $\mathrm{Sn}-\mathrm{Pb}$ solder powder were investigated. The rapidly solidified eutectic $\mathrm{Sn}-\mathrm{Pb}$ solder powder exhibited instability after aging at different temperatures. Pb-rich phase coarsening was observed, during which the small particles congregated to form large particles in the microstructure. At elevated temperatures, similar coarsening of the $\mathrm{Pb}$-rich phase occurred considerably more rapidly, because of the increase in mass transport. The relationship between $\mathrm{Pb}$-rich phase coarsening and the aging temperature was estimated using the Arrhenius law. The activation energy obtained for the processes was $45.53 \pm 4.23 \mathrm{~kJ} / \mathrm{mol}$, indicating that the rapid diffusion mechanism has a low activation barrier for $\mathrm{Pb}$-rich phase coarsening. Moreover, the estimated value of the activation energy indicates that 
mass transport controlled through grain boundary diffusion is crucial for Pb-rich coarsening under aging treatment.

Author Contributions: Investigation, J.Y., D.Z. and Y.L.; Supervision, J.Y. and J.X.; Writing—original draft, J.Y.

Funding: This study was supported by the National Key R\&D Program of China (2017YFB1104300; 2018YFB1107200), the National Natural Science Foundation of China (51775303) and Beijing science and technology project (2014JH29).

Conflicts of Interest: The authors declare no conflict of interest.

\section{References}

1. Zeng, J.; Chen, W.; Yan, W.; Yang, Y.; McLean, A. Effect of permanent magnet stirring on solidification of sn-pb alloy. Mater. Des. 2016, 108, 364-373. [CrossRef]

2. Manko, H.H. Solders and Soldering; McGraw-Hill: New York, NY, USA, 1964.

3. Frear, D.R.; Burchett, S.N.; Morgan, H.S.; Lau, J.H. Mechanics of Solder Alloy Interconnects; Springer Science \& Business Media: New York, NY, USA, 1994.

4. Sharif, A.; Chan, Y.; Islam, R.A. Effect of volume in interfacial reaction between eutectic $\mathrm{Sn}-\mathrm{Pb}$ solder and $\mathrm{Cu}$ metallization in microelectronic packaging. Mater. Sci. Eng. B 2004, 106, 120-125. [CrossRef]

5. Wang, H.; Zhao, H.; Sekulic, D.P.; Qian, Y. A comparative study of reactive wetting of lead and lead-free solders on cu and (cu 6 sn 5 /cu 3 sn)/cu substrates. J. Electron. Mater. 2008, 37, 1640-1647. [CrossRef]

6. Garcia, L.R.; Osório, W.R.; Peixoto, L.C.; Garcia, A. Wetting behavior and mechanical properties of sn-zn and sn-pb solder alloys. J. Electron. Mater. 2009, 38, 2405-2414. [CrossRef]

7. Wei, C.; Liu, Y.C.; Han, Y.J.; Wan, J.B.; Yang, K. Microstructures of eutectic sn-ag-zn solder solidified with different cooling rates. J. Alloy. Compd. 2008, 464, 301-305. [CrossRef]

8. Chu, M.G.; Shiohara, Y.; Flemings, M.C. Solidification of highly undercooled sn-pb alloy droplets. Metall. Trans. A 1984, 15, 1303-1310. [CrossRef]

9. Li, S.; Wu, P.; Zhou, W.; Ando, T. Kinetics of heterogeneous nucleation of gas-atomized sn-5 mass $\% \mathrm{pb}$ droplets. Mater. Sci. Eng. A 2008, 473, 206-212. [CrossRef]

10. Li, S.; Wu, P. Prediction of solidification behavior of gas-atomized sn-5mass $\%$ pb droplets. Multidiscip. Model. Mater. Struct. 2013, 9, 514-523. [CrossRef]

11. Dunkley, J.; Aderhold, D. Centrifugal atomization of metal powders. Adv. Powder Metall. Part. Mater. 2007, 1, 02-26-02-31.

12. Plookphol, T.; Wisutmethangoon, S.; Gonsrang, S. Influence of process parameters on sac305 lead-free solder powder produced by centrifugal atomization. Powder Technol. 2011, 214, 506-512. [CrossRef]

13. Minagawa, K.; Kakisawa, H.; Osawa, Y.; Takamori, S.; Halada, K. Production of fine spherical lead-free solder powders by hybrid atomization. Sci. Technol. Adv. Mater. 2005, 6, 325-329. [CrossRef]

14. Lampe, B. Room temperature aging properties of some solder alloys. Weld. J. 1976, 55, 330.

15. Matin, M.; Vellinga, W.; Geers, M. Aspects of coarsening in eutectic sn-pb. Acta Mater. 2004, 52, 3475-3482. [CrossRef]

16. Gan, K.; Ngan, A. The unusual size effect of eutectic sn/pb alloys in the micro regime: Experiments and modeling. Acta Mater. 2018, 151, 282-292. [CrossRef]

17. Cruz, H.; Ramírez-Argaez, M.; Juarez, A.; Garcia, A.; González-Rivera, C. Fourier thermal analysis of the eutectic formed in pb-sn alloys. J. Mater. Eng. Perform. 2009, 18, 441-445. [CrossRef]

18. Zhao, L.; Xu, F.; Lu, D.; Dong, W.; Li, Y.; Kawasaki, A. Simulation of 63sn-37pb bga packaging particle formation based on pulsated orifice ejection method (poem). In Proceedings of the 2013 14th International Conference on Electronic Packaging Technology, Dalian, China, 11-14 August 2013; pp. 338-342.

19. Harris, P.; Chaggar, K.; Whitmore, M. The effect of ageing on the microstructure of 60: 40 tin-lead solders. Solder. Surf. Mount Technol. 1991, 3, 20-33. [CrossRef]

20. Yang, C.; Gao, J.; Zhang, Y.; Kolbe, M.; Herlach, D. New evidence for the dual origin of anomalous eutectic structures in undercooled ni-sn alloys: In situ observations and ebsd characterization. Acta Mater. 2011, 59, 3915-3926. [CrossRef]

21. Jung, K.; Conrad, H. Microstructure coarsening during static annealing of 60sn40pb solder joints: I stereology. J. Electron. Mater. 2001, 30, 1294-1302. [CrossRef] 
22. Senkov, O.; Myshlyaev, M. Grain growth in a superplastic zn-22\% al alloy. Acta Metall. 1986, 34, 97-106. [CrossRef]

23. Okkerse, B. Self-diffusion in lead: I. Lattice and grain-boundary diffusion. Acta Metall. 1954, 2, 551-553. [CrossRef]

24. Gupta, D.; Vieregge, K.; Gust, W. Interface diffusion in eutectic pb-sn solder. Acta Mater. 1998, 47, 5-12. [CrossRef]

(c)

(C) 2019 by the authors. Licensee MDPI, Basel, Switzerland. This article is an open access article distributed under the terms and conditions of the Creative Commons Attribution (CC BY) license (http://creativecommons.org/licenses/by/4.0/). 